\title{
Escola especial: Uma realidade a ser desvendada
}

\author{
Special school: a reality to be unveiled
}

\author{
Elizabeth Carvalho da Veiga ${ }^{[a]}$, Andréa Cristina Senger Netto ${ }^{[b]}$, Adriana Olenik da Cruz ${ }^{[\mathrm{c}]}$, \\ Roseli Koehler $^{[\mathrm{d}]}$, Waléria Schwartzbach ${ }^{[\mathrm{e}]}$
}

[a] Doutora em Psicologia Cognitiva, professora da Graduação e da Pós-Graduação da Pontifícia Universidade Católica do Paraná (PUCPR), Curitiba, PR - Brasil, e-mail: bethveiga@hotmail.com

[b] Psicóloga com Especialização em Educação Inclusiva pela Faculdade Internacional de Curitiba (FACINTER), Curitiba, PR - Brasil.

[c] Psicóloga com Especialização em Educação Inclusiva pela Pontifícia Universidade Católica do Paraná (PUCPR), Curitiba, PR - Brasil.

[d] Professora com Especialização em Educação Inclusiva pelas Faculdades Integradas de Jacarepaguá (FIJ), Rio de Janeiro, RJ - Brasil.

[e] Professora com Especialização em Educação Inclusiva pelo Centro Internacional de Pesquisa, Pós-Graduação e Extensão (CIPPEX), Guaratuba, PR - Brasil.

\section{Resumo}

Partindo dos estudos de Sternberg, com a Teoria Triárquica, e de Gardner, das Inteligências Múltiplas, que integram muito bem os dados disponíveis no campo da inteligência, desenvolveu-se uma pesquisa com o objetivo de identificar, na educação especial, o uso das habilidades cognitivas que envolvem a inteligência analítica. A necessidade da implantação deste projeto de pesquisa surgiu após a aplicação de um projeto piloto que visou a implementar o uso das oito inteligências na aprendizagem acadêmica, envolvendo a inteligência prática. Esta pesquisa ocorreu em uma escola especial (Escola de Educação Especial Professora Roza Bini de Oliveira) em Almirante Tamandaré, PR, cujo público-alvo foi composto de 16 alunos que apresentaram por escrito uma indicação de necessidades especiais, por parte de um especialista em educação especial ou outro profissional apto a realizar essa indicação. São alunos com necessidades especiais moderadas, do sexo masculino e feminino, de qualquer cor e com nível socioeconômico baixo. Esta atividade consistiu em aplicar individualmente várias questões que contemplavam as diversas habilidades do processo de metacomponentes de planejamento da inteligência analítica relacionando-os com os oito sistemas inteligentes. A experiência mostrou que esses alunos aprendem por condicionamento e que essas aprendizagens estão ligadas a situações e vivências de atividades de rotina. Percebe-se que a capacidade de analisar e solucionar, por condicionamento, questões que se encontram fora das aprendizagens anteriormente adquiridas não foi possível, mostrando que os alunos não conseguiram integrar as capacidades práticas com as capacidades analíticas, pois o condicionamento mostrou ser pontual, não propiciando a generalização.

Palavras-chave: Educação especial. Aprendizagem. Inclusão. Inteligências. 


\begin{abstract}
Starting from Sternberg's studies on the Triarchic Theory and Gardner's Theory of Multiple Intelligences, which properly integrate the available data in the field of intelligence studies, it was developed a research with the aim of identify the use of cognitive abilities, including analytical intelligence. The need for this research project appeared after the application of a pilot project that aimed to implement the use of the eight intelligences in academic learning, including practical intelligence. This research occurred in a special school in the town of Almirante Tamandaré, in the state of Parana, Brazil, and has taken as its target 16 students from Special Education School Professor Roza Bini de Oliveira, who was officially declared as bearers of special needs by some expert in special education or another professional fitted for writing such declaration. They are students with moderate special needs, male or female, independently of skin color, and from lower social and economic levels. This activity consisted in asking each student several questions regarding the abilities implied in the process of planning metacomponents of the analytical intelligence, relating them to the eight intelligent systems. The experiment showed that those students learn by conditioning, and that those learnings are linked to situations and experiences from the routine activities. It is realized that the ability of analyze and solve questions that are beyond the previously acquired conditioning learned abilities was not possible, showing that the students were not able to integrate both practical and analytical capacities, since conditioning becomes specific and does not favors generalization.
\end{abstract}

Keywords: special education, learning, inclusion, intelligences.

\section{Introdução}

De acordo com a Declaração de Salamanca na Conferência Mundial sobre Necessidades Educacionais Especiais, há o relato de que as escolas devem acolher a todas as crianças, incluindo crianças com deficiências, superdotadas, de rua, que trabalham, de populações distantes, nômades, pertencentes a minorias marginalizadas. Para isso, sugere-se que se desenvolva uma pedagogia centrada na relação com a criança, capaz de educar com sucesso a todos, atendendo às necessidades de cada um, considerando as diferenças existentes entre elas.

No Brasil, a Lei n. 9.394/96 estabelece as Diretrizes e Bases da Educação Nacional e o Documento subsidiário à política de inclusão define a educação especial como:

uma modalidade de educação escolar que permeia todas as etapas e níveis de ensino [...]. Permite também, tomar a educação especial como um recurso que beneficia a todos os educandos e que atravessa o trabalho do professor com toda a diversidade que constitui o seu grupo de alunos (Paulon, de Lucca Freitas \& Pinho, 2005, p. 19).
A educação especial vem despertando estudos e pesquisas no sentido de aprofundar métodos de igualdade e inclusão, em que o aluno com necessidades especiais seja considerado no ambiente escolar como capaz de interagir e de se desenvolver. Interessa a todos a identificação de melhores e mais adequados processos educacionais que reconheçam as necessidades especiais de determinados alunos sob os ângulos de desenvolvimento e de interação com os diversos segmentos da vida.

A escola deve possibilitar ao aluno o desenvolvimento de suas possibilidades de forma que possa intervir posteriormente no processo sociocultural e inovar a sociedade. Sua função consiste em provocar desequilíbrios e fazer desafios, levando o aluno a trabalhar o mais independentemente possível. As crianças devem ser encorajadas a explorar o seu ambiente, bem como a si próprias, expressando por meio dos vários sistemas inteligentes sua percepção de mundo, ideias e ações. É importante pensar no que fazer para educar as crianças dentro de sua cultura e atender às expectativas que a escola onde estão inseridas se propõe a desenvolver. Devem-se criarcondições favoráveis para o desenvolvimento cognitivo mediante os processos de aprendizagem, levando em conta a mediação ou interação sociocultural na relação professor-criança e também na relação criança-criança. 
Segundo Gardner (1994,1995), temos sólidas evidências de que a mente humana é um sistema multifacetado, de múltiplos componentes. A inteligência foi definida operacionalmente como a capacidade de responder a itens em testes de inteligência. A partir das pesquisas de Gardner, que culminam em sua obra Estrutura da mente, a inteligência é compreendida como a capacidade de resolver problemas ou elaborar produtos que são importantes num determinado ambiente ou comunidade cultural. Gardner propõe uma teoria modular da mente, denominada Teoria das Inteligências Múltiplas, na qual são apresentadas nove inteligências: linguística, lógico-matemática, naturalista, existencial, interpessoal, intrapessoal, cinestésica-corporal, espacial e musical, sendo a existencial considerada como hipótese.

Tal teoria questiona a concepção de inteligênciaúnica, enfatizando oito diferentes inteligências, estas, por sua vez, potencializam o desenvolvimento do sistema mental, valorizando o ser humano em todas as suas capacidades. Gardner (1992 citado por Veiga; Garcia, 2006, p. 55) afirma que "ao nascer, os indivíduos podem apresentar perfis particulares de inteligência que os diferencia entre si e que estes perfis se modificam ao longo do desenvolvimento do sujeito".

A mente segundo a teoria modular está constituída por um conjunto de módulos e cada módulo é específico e especializado em um tipo de processo ou atividade com um funcionamento relativamente independente e atuando em paralelo. Cada módulo (inteligência) tem memórias, regras procedimentais e conteúdos pré-programados inatamente (herança genética), os quais são influenciados conforme a estimulação que o meio oferece.

É na primeira infância que os sistemas intelectuais começam a ser simbolizados pelas inteligências inatas. Segundo Antunes (2002, p. 49), não nascemos com capacidades estimuladas e com competências definitivas, porém, de nossa história genética trazemos traços de espectros de nossas inteligências.

A educação éa base para o desenvolvimento da criança. Seus objetivos dividem-se em:

- Cognitivos - interagir com o ambiente, estruturando o conhecimento físico, o lógico-matemático e o social; ampliar a capacidade de comunicação de pensamentos e de sentimentos por meio das formas de expressão simbólica.
- Afetivos - interagir empaticamente com os pares e com os adultos; desenvolver atitudes de autoconfiança, iniciativa, responsabilidade eindependência;incorporar normas de conduta social.

- Motores - coordenar inteligentemente a ação corporal, percebendo as suas possibilidades e limitações; utilizar o corpo como elemento de comunicação.

Fazendo um paralelo com a Teoria das Inteligências Múltiplas, percebe-se que os objetivos anteriormente citados fazem referência aos oito sistemas inteligentes.

O importante na Teoria das Inteligências Múltiplas é o emprego das inteligências, juntas ou separadas, para realizar tarefas valorizadas em uma sociedade (Gardner, 1994). Todas as pessoas nascem com as inteligências, que são pré-programadas geneticamente e passíveis de mudanças por meio da aprendizagem, da experiência e da cultura. Com isso, a escola deve estar preparada para atender às diferenças dos alunos, tentando garantir que cada pessoa consiga revelar seu potencial. Dessa forma, a escola deve buscar uma educação centrada no indivíduo e levar a sério as inclinações e habilidades de cada aprendiz.

De acordo com Gardner (1998, 1999, 2000, 2001), os numerosos estudos realizados sobre a cognição humana apresentam fortes evidências de que a mente é multifacetada e que não pode ser capturada em um simples instrumento, como lápis e papel. A teoria baseia-se em um potencial biológico, o qual expressa o resultado da integração dos fatores genéticos e ambientais. Tal teoria assume a existência de várias competências intelectuais humanas, denominando-as de "inteligências".

Gardner (1992) apresenta as inteligências como uma nova definição da natureza do ser humano, em que o descreve como um organismo que possui um conjunto básico de inteligências desde o ponto de vista cognitivo. Não existem duas pessoas com o mesmo perfil, pois as inteligências surgem da combinação da herança genética das pessoas e suas condições de vida em uma cultura ou época, portanto, todos temos uma combinação exclusiva de inteligências.

Segundo Gardner (1994), o mais importante não é valorizarmos quantas inteligências temos, mas o desenvolvimento de todas elas, segundo as nossas 
vontades e aptidões. Acredita-se que alguns talentos se desenvolvem apenas porque são valorizados pelo meio em que estão inseridos e que muitas habilidades do ser humano não são descobertas porque não recebem os estímulos adequados, pois quanto maior a motivação maior é o desempenho.

Gardner (1988 citado por Armstrong, 2001, p. 13) afirma: "é de máxima importância reconhecer e estimular todas as variadas inteligências humanas e todas as combinações de inteligências. Nós somos todos tão diferentes, em grande parte, porque possuímos diferentes combinações de inteligências".

Segundo Armstrong (2001), ao identificar as forças e o estilo de aprendizagem preferido de um aluno, essa informação pode servir como base para decidir que tipos de intervenção são mais apropriados para a inclusão de um programa educacional individualizado.

Dentro de uma visão multifacetada da inteligência encontra-se Sternberg (1986,1987,1990, 1992, 1997 citado por Veiga, Garcia, 2006, p. 65), que propõe em sua teoria da inteligência tridimensional que:

para desenvolver e compreender a inteligência humana, o modelo teórico põe em relação o mundo interno da pessoa ou os processos mentais que destacam a conduta inteligente e o papel mediador das relações que ao longo da vida se estabelecem entre o mundo interno e o mundo externo do indivíduo e atividade mental na vida diária para resolver os problemas que o meio propõe.

Sternberg apresenta, em sua Teoria Triárquica, o desenvolvimento intelectual com base em três subteorias relacionadas entre si. As três unidades apresentadas em sua teoria são: inteligência componencial ou analítica, inteligência experiencial ou criativa e inteligência contextual ou prática.

A inteligência analítica ou componencial analisa os componentes e os processos mentais que explicam a atividade inteligente de uma pessoa. Essa dimensão relaciona a inteligência ao mundo interior do sujeito, identificando os processos mentais, ou seja, estruturas e mecanismos que regem um comportamento inteligente. Essa competência revela uma capacidade para analisar, criticar e avaliar.

A inteligência criativa ou experiencialestá relacionada com a vida mental do sujeito e suas experiências, descrevendo a conduta inteligente quando o indivíduo enfrenta situações novas. Ela foi desenvolvida para abordar o aspecto da inteligência que faltava na subteoria analítica. Tal aspecto diz respeito ao papel da experiência no desempenho inteligente, responsável pela capacidade de criar, inventar.

A inteligência prática ou contextual é a capacidade de relacionar a vida mental do sujeito com seu meio e adaptação ao ambiente, a transformação deste ou a seleção de um ambiente alternativo. Aqui, a inteligência prática mostra a capacidade que o sujeito tem de utilizar, aplicar e se adaptar a diferentes situações.

Os pensamentos analítico, criativo e prático estão presentes em diferentes situações do cotidiano do sujeito. $\mathrm{O}$ analítico está mais presente nos problemas abstratos ou do tipo acadêmico; o criativo invoca problemas novos; e o prático está ligado a problemas concretos mais familiares ao sujeito. Segundo Sternberg (2003), utilizando de forma equilibrada as três capacidades o indivíduo torna-se plenamente inteligente, reconhecendo suas forças e aproveitando-as ao máximo, da mesma forma que conhece suas fraquezas e descobre maneiras para compensá-las.

Todos os alunos têm o direito de que lhes sejam oferecidas oportunidades educacionais nas condições mais desafiadoras e favoráveis possíveis, que estabeleçam contato e socialização com os colegas e lhes permitam, no futuro, integrar-se e participar da sociedade.

As questões da educação especial dos chamados "alunos especiais" caracterizam-se pela defasagem e pelas alterações nas estruturas mentais para aquisição de conhecimento sistemático. Contudo, ao longo de suas vidas, tais alunos aprendem diversas atividades para sua sobrevivência.

Este artigo surgiu, tendo como iniciativa compartilhar a nossa experiência com o processo de aprendizagem em escola especial, após a prática resultante de um grupo de pesquisa nessa área, grupo esse preocupado com a realidade da inclusão escolar com responsabilidade e com a verdadeira aquisição de conhecimentos por parte dos alunos com necessidades educativas especiais.

Queremos socializar nossas reflexões, nossos questionamentos, nossas dúvidas e descobertas com os colegas da área, que, a nosso ver, deverão repensar sua práxis e vivenciar todo o turbilhão emocional que essa tarefa apresenta. 
Dentro dessa visão múltipla da inteligência, ressalta-se o quanto o ser humano pode ter um bom desenvolvimento e o quanto a educação deixa a desejar por valorizar o indivíduo apenas por dois sistemas, o linguístico e o lógico-matemático. A educação deve ser incansavelmente mediadora de estímulos, elevando o potencial do seu aluno e valorizando cada habilidade. É importante que não haja supervalorização apenas de duas aptidões, mas um trabalho contínuo e conjunto, no qual cada inteligência deve ser potencializada e explorada.

Noâmbito educacional, há que se favorecer a construção consciente e autônoma de formas pessoais de identidade e de pensamento, por intermédio da implementação de estratégias e procedimentos de ensino e de aprendizagem diversos e flexíveis, com o objetivo de responder a uma realidade que é heterogênea e, consequentemente, contribuir para a melhoria das relações socioculturais (Martinez \& Suñé, 1999).

\section{Metodologia}

\section{Populaçáo}

Alunos entre 7 e 15 anos que possuam necessidades educativas especiais.

\section{Amostra}

A amostra é composta por 16 alunos da Escola de Educação Especial Professora Roza Bini de Oliveira, que apresentaram por escrito umaindicação de necessidades especiais, por parte de um especialista em educação especial ou outro profissional apto a realizar essa indicação. Todos apresentam deficiência mental moderada, são do sexo masculino e feminino, de qualquer cor, com nível socioeconômico baixo.

\section{Procedimentos}

Adotando a teoria de Gardner e Sternberg como base para promover um novo modelo de aprendizagem, em 2007 foi desenvolvido um estudo na Escola de Educação Especial Professora Roza Bini de Oliveira com proposta inicial de avaliar e distribuir todos os alunos em três níveis, dentro das oito inteligências, tendo como classificação: nível I - baixo desenvolvimento cognitivo; nível II desenvolvimento cognitivo parcial; e nível III - bom desenvolvimento cognitivo. O critério de avaliação utilizado foi o desempenho do aluno sob o ponto de vista do professor.

Foram criados ambientes para cada inteligência, os alunos faziam rodízio nesses ambientes e o professor trabalhava de acordo com o nível cognitivo de cada criança. Ao final desse ano de estudo, o resultado principal evidenciou que os alunos especiais dessa escola necessitam de maior vínculo e referência para construir suas aprendizagens.

Esse indicativo propôs que se trabalhasse com uma amostragem menor para o projeto piloto em 2008. Decidiu-se que participariam duas turmas com no máximo 15 alunos entre 7 e 15 anos e com deficiência mental moderada. Os resultados obtidos com o estudo e a aplicação da teoria de Gardner, durante a primeira fase, foram adotados também com a teoria de Sternberg, integrando as oito inteligências e a inteligência prática. Desenvolveram-se, para este estudo, ambientes modulares representando locais de convívio e de vida diária dos alunos.

Esses ambientes foram elaborados no espaço escolar, representando locais da vida diária dos alunos que faziam parte da pesquisa, como mercado, posto de saúde, terminal de ônibus, festas com temáticas comuns a esses alunos.

Nesse período, os alunos demonstraram interesse e conhecimento pelos ambientes construídos, porém, não houve aprendizagem, em razão de os alunos não interpretarem e internalizarem o espaço como vivência real. Não ocorria o faz de conta comum em brincadeiras infantis, apenas a exploração dos ambientes e dos objetos de forma aleatória, não havendo a generalização entre o ambiente simulado e o real.

A avaliação mostrou, como resultado, que a aprendizagem é condicionada por meio da repetição e sistematização de atividades do dia a dia.

Em 2009, pretendeu-se desenvolver competências de resolução de problemas, de forma sistêmica e estruturada, com a preocupação de reforçar áreas preservadas cognitivamente, sustentando com mais segurança a motivação e a autoestima dos alunos.

Nesse momento, a proposta era trabalhar os espaços externos ao ambiente escolar, proporcionando ao aluno a vivência nos locais de seu dia a dia, como o mercado, o terminal de ônibus e outros espaços. 
Novamente, pôde-se observar que a aprendizagem não ocorreu. $\mathrm{O}$ aluno ao vivenciar os locais obteve uma resposta positiva, de que o mercado é para fazer compras, o terminal é para pegar ônibus, porém, ao retornar ao ambiente escolar e realizar um relato da importância da atividade, as respostas foram aleatórias, não conseguindo obter um resultado de internalização e generalização da aprendizagem com a vivência real, demonstrando novamente que a aprendizagem para alunos com deficiência mental moderada só ocorre por meio de condicionamento diário.

Este trabalho resultou na compreensão, diante das dificuldades encontradas por parte da nossa clientela, no uso da inteligência prática, que é universal e relativa quanto à cultura, já que a conduta valorizada como habilidade, adaptada, seletiva ou transformadora muda segundo os contextos socioculturais. Os alunos tiveram muita dificuldade em simbolizar e assim construir estratégias de intervenção com base na inteligência prática.

Em 2010, seguindo essa visão pluralista da mente, sabe-se que a inteligência não é uma atividade mental cega ou aleatória, ao contrário, nela dirige-se propositalmente a execução de determinados objetivos para satisfazer as necessidades concretas e específicas na vida das pessoas.

Pensando em inclusão e diante das dificuldades encontradas durante esses anos, decidiu-se investigar as habilidades que fazem parte de um dos processos mentais que compõem a inteligência analítica, que são os metacomponentes de planejamento.

Esta atividade consistiu em aplicar uma série de atividades envolvendo as cinco habilidades de Sternberg, do pensamento analítico referente ao metacomponente de planejamento, relacionando cada um deles com as oito inteligências de Gardner.

A psicóloga responsável pela escola chamou individualmente cada criança e aplicou as atividades previamente elaboradas. Essas atividades consistiam em uma série de perguntas elaboradas e baseadas nas oito inteligências, reforçando apenas o conhecimento adquirido durante sua vida, envolvendo o seu cotidiano, tendo como resposta ações que representavam seu conhecimento em situações de envolvimento diário. Constatou-se, com as respostas obtidas, que não existe generalização do conhecimento, demonstrando que o aluno pesquisado não correlaciona as situações simples se estas não são exatamente iguais às que ocorrem em seu cotidiano.

\section{Resultados e discussáo}

\section{A escola}

Para os alunos de educação especial, o mundo do conhecimento na escola está centrado na sua singularidade, e não na aprendizagem sistemática, a qual envolve processos cognitivos da inteligência analítica.

Promover para esses educandos a aplicabilidade de estratégias cognitivas em situações reais de vida prática, planejando uma metodologia de intervenção centrada no desenvolvimento das potencialidades do aluno especial, nos pareceu uma tarefa fácil. Num primeiro momento, não haveria maiores dificuldades, pensamos nós, profissionais cheios de vontade em buscar metodologias eficazes para a aprendizagem de nossos alunos. Tinha-se uma única pergunta, essa aprendizagem seria fruto de processos cognitivos das inteligências analítica, prática e criativa ou seria uma aprendizagem de nível operante, limitada no que se refere à capacidade de generalizar, necessitando ser constantemente repetida, pois, caso contrário, se extinguiria. Estávamos dispostas a investir numa nova proposta de aprendizagem para essa clientela que não fosse o condicionamento.

Ao longo dos quatro anos de nossa pesquisa muitos foram os entraves observados na execução do trabalho planejado. A aprendizagem que obtínhamos apresentava a forte tendência a não se estabilizar, ou seja, o aprendido hoje não era mantido amanhã. Não tínhamos a estimulação da família na aquisição de novas aprendizagens e, à medida que avançávamos, percebemos claramente a necessidade da repetição para a manutenção do que era aprendido. Definitivamente estávamos sós nesta caminhada!

A imersão no mundo de aprendizagem de nossas crianças gerou muitas dúvidas, incertezas, descobertas, angústias, frustrações, medos, esperanças. E agora o que fazer? Nossas convicções foram postas à prova e desafiadas a cada momento. $\mathrm{O}$ mundo do conhecimento sistemático parecia inatingível! $\mathrm{Na}$ escola, bastavam as férias do mundo acadêmico para que os temas desenvolvidos durante horas, dias, meses e anos voltassem à estaca zero.

Nossa sala de estudo já não parecia tanto um local confortável e de certezas, e sim um espaço onde o grupo de estudo procurava em conjunto 
descobrir as verdadeiras potencialidades de nossos alunos e elaborar alternativas de intervenção educativa nessa escola. Inacreditavelmente, metodologias de intervenção educativa eram criadas a cada momento, porém, lá estavam eles executando tarefas com mais ou menos sucesso, mas por puro condicionamento, de maneira discriminativa, levando-os a uma aprendizagem limitada, sem abstrair, generalizar.

Muitos são os exemplos dessa aprendizagem por condicionamento, como poderemos observar no relato a seguir: em uma das tardes, com o grupo reunido, estava a professora com seu plano de aula, que contemplava a inteligência corporal-cinestésica. Ela iniciou o trabalho com os alunos, tal trabalho tinha como objetivo o esquema corporal. Em síntese, as etapas envolviam a exploração das partes do corpo e suas funções, o reconhecimento das diferentes partes do corpo no espelho, a reprodução do corpo humano em um jogo de encaixe. Depois de uma sequência de vários dias trabalhando o esquema corporal, a professora interveio com uma atividade para avaliar o que as crianças tinham aprendido. $\mathrm{Na}$ investigação das funções, a professora perguntou a um deles: para que serve a boca? A resposta veio prontamente: para comer. Volta a professora a perguntar: e para que mais serve a boca, além de comer? Veio um silêncio ensurdecedor. A resposta caracteriza uma aprendizagem por condicionamento operante, discriminativo, ou seja, só para comer, sem perceber outras funções, como falar, por exemplo.

Nossa luta era diária, o mínimo avanço na aquisição de processos cognitivos era como se tivéssemos vencido a primeira batalha, mas estávamos cientes de que ainda não estava vencida a guerra.

O mundo do conhecimento era um velho conhecido, em que a aprendizagem era decorrente de uma classe de respostas semelhantes topograficamente, ou seja, era pela forma ou função que a experiência prática das vivências de nossos alunos garantia sua interação no processo de aprendizagem.

O condicionamento seria o único processo que poderia se utilizar para elas aprenderem? Infelizmente as repetições das experiências eram poucas, pouquíssimas, pois a debilidade das famílias eram enormes em todos os sentidos, e o pouco conhecimento adquirido era extinto facilmente. Portanto, o repertório que compunha a inteligência prática deles era mínimo.

\section{A busca da inteligência analítica}

Sendo a escola especial um espaço de aprendizagem não só assistemática, mas com o foco no ensino regular, tinha-se efetivamente que buscar a inteligência analítica de nossas crianças, pois é ela que garante o sucesso no desempenho acadêmico. A inclusão torna-se difícil sem a compreensão do sistema inteligente que garante o sucesso de nossas crianças nessa nova escola.

Buscamos nos apoiar em conceitos claros e definidos por autores de renome nacional e internacional. $\mathrm{O}$ primeiro passo foi definir o que o grupo compreendia por aprendizagem. Segundo Visca (1987), a aprendizagem é entendida como o aparecimento e a estabilização de uma conduta. Muitas foram as intervenções em busca dessa aprendizagem, porém, bastava um feriado, a conduta adquirida desaparecia e as professoras começavam tudo de novo. Percebe-se que existe o aparecimento da conduta, porém, esta não se estabiliza. Por outro lado, algumas aquisições ocorrem por meio de um condicionamento operante e se mantêm desde que sejam constantemente trabalhadas, caso contrário desaparecem. Dentro do enfoque behaviorista, pode-se dizer que houve uma aprendizagem discriminativa, a qual não oportuniza generalizações.

Contudo, o nosso grupo estava centrado numa concepção cognitivista, com base na teoria de Sternberg, buscando os processos cognitivos da inteligência analítica, a qual responde pela aprendizagem acadêmica, possibilidade essa sonhada por muitas famílias das crianças envolvidas nesta pesquisa. No mundo do conhecimento dessas crianças estavam presentes algumas aprendizagens fruto do condicionamento. Nossa pergunta era: até quando essa aprendizagem estará fazendo parte do repertório dessa criança?

Nossa sala de estudo não era mais um lugar seguro para acolher nossas certezas, estava inundada de dúvidas, muitas perguntas e poucas respostas, mas não desistíamos diante de nossas angústias, estas se tornaram o combustível para enfrentar o desafio que nos impusemos.

A pesquisa mostrou que o processo mental do pensamento analítico, denominado metacomponentes de planejamento, é composto pelo processamento da informação que envolve os seguintes processos mentais: identificar o problema; distribuir recursos; representar e organizar informações; 
formular estratégias; e monitoramento e avaliação das estratégias de solução de problemas, já que nossa clientela tem muitas dificuldades.

Nosso público-alvo, com necessidades especiais moderadas, apresentou habilidade comprometida para clarificar a natureza doproblema e determinaro que se necessitapara resolvê-lo. Na execução das atividades, sempre se faz necessária não apenas uma orientação prévia, para que seja compreendida a tarefa solicitada, mas um direcionamento do raciocínio, exigido pela atividade, com a referência externa.

Para sua execução é necessária a mediação que, atribuindo estratégias de pensamento de "fora para dentro", direciona as alternativas para solucionar o problema. A compreensão da situação problemática é permitida pela representação mental que possui da informação. A representação mental envolve, além da imagem ligada à percepção das coisas, objetos e fenômenos, as atribuições feitas pelos sujeitos às imagens.

Nossa primeira descoberta foi a de que nossa clientela possui dificuldade na representação mental, aquisição, segundo Piaget (1958), adquirida no final do nível sensório motor. Isso acaba interferindo diretamente na compreensão do problema, bem como na elaboração das estratégias para solucioná-lo.

Sem o simbólico, nada é pensável. Nesse momento a sensação é de que havíamos perdido uma batalha, mas não a guerra. Continuamos a investigar as demais habilidades que compõem os processos mentais da inteligência analítica, o que corresponde à aprendizagem acadêmica.

A distribuição de recursos mentais adequados (motivação, conhecimentos, atenção) nem sempre é utilizada de forma consciente, o que dificulta essa distribuição, pois ela implica a regulação e o uso consciente desses recursos. Nesse momento de nossa caminhada, encontraram-se crianças com uma variação na motivação e na capacidade de manter a atenção e um mundo de conhecimento fruto de sua vida prática por meio de condicionamento.

Quanto à habilidade de formular estratégias, observou-se um impedimento em eleger estratégias para enfrentar a problemática, pois não compreendia-se qual era o problema, independente do sistema inteligente (linguístico, lógico-matemático, espacial, corporal-cinestésico, entre outros). As estratégias não se fazem presentes, as crianças agem sob a mediação ou executam a atividade de forma indiscriminada com base numa aprendizagem condicionada.
Em relação ao monitoramento e avaliação das estratégias, essa habilidade também se apresentou com defasagens, pois a criança apenas executava a atividade sem estar presa à estratégia escolhida, avaliando-a antes de aplicá-la, simplesmente dando sua resposta, quando esta encontrava-se no rol das aprendizagens condicionadas.

$\mathrm{Na}$ habilidade de supervisão de soluções, incluem-se todas as modificações necessárias durante o processo, desde o ato de planificar até conseguir a meta desejada. A prática demonstrou a inabilidade das crianças no uso dessa capacidade, pois ao término das tarefas eles não avaliam sua produção. $\mathrm{O}$ fazer é pelo fazer sem preocupação com estratégias de execução que podem levar a melhores resultados.

A experiência mostrou que, no processo mental denominado metacomponentes e suas habilidades, as quais são exigidas no mundo acadêmico, as crianças com necessidades especiais moderadas apresentam-se inaptas, o que justifica sua dificuldade de aprender, ou seja, de estabilizar a nova conduta. O que se alcança é o aparecimento da conduta, mas não a sua estabilização. A criança especial utiliza-se da imitação diferida para repetir modelos, o que pode levar a uma pseudoaprendizagem. No processo de aprendizagem dessas crianças a referência é externa e não interna, por isso eles não simbolizam, apenas repetem um comportamento, e este é mantido desde que seja sempre repetido.

\section{Consideraçóes finais}

Neste momento, saímos do nosso mundo de certezas e estamos envolvidas por nossos questionamentos, inseguranças, com medo de que tudo aquilo que observamos e concluímos seja realmente a realidade. Saímos do mundo das ilusões, onde o ensino sistemático para todos era possível. Sim, era possível um mundo de conhecimento acadêmico advindo da inteligência analítica, porém, nossas crianças apresentaram-se cada vez mais longínquas do mundo da aprendizagem sistemática, pois os processos cognitivos que garantem a aprendizagem nesse contexto apresentam-se comprometidos.

Considera-se que a criança com necessidades educativas especiais moderadas apresenta significativos obstáculos nos processos mentais, que respondem pela inteligência acadêmica, pois as habilidades exigidas por esses processos, na sua 
maioria mostram-se ausentes e, com isso, questiona-se a viabilidade da aprendizagem acadêmica.

O mundo da aprendizagem sistemática requer o desenvolvimento da inteligência analítica para garantir o seu sucesso. Verificou-se que a aprendizagem compreendida como aparecimento e a estabilização de conduta não ocorrem. Esta pesquisa revelou que o surgimento de novas condutas é viável, porém, estas não se estabilizam e tão pouco se generalizam. Portanto, acredita-se que se pode desenvolver aprendizagem nessas crianças que esteja relacionada com a inteligência prática e não com a analítica, pois esta se mostra como pseudoaprendizagem.

Dentro deste estudo, concluiu-se que esses alunos com deficiência aprendem por condicionamento, levando em consideração que essa aprendizagem está ligada a situações e vivências de atividades de rotina. Nessa última fase do estudo, observou-se que a entrada da inteligência analítica foi um grande desafio, pois demonstrou que a capacidade de analisar e solucionar questões fora do condicionamento já anteriormente trabalhado não foi possível, mostrando que os alunos não conseguem integrar as capacidades práticas com as capacidades analíticas, pois o condicionamento passa a ser pontual e não faz generalização, tornando-se difícil a construção do conhecimento.

\section{Referências}

Antunes, C. (2002). Novas maneiras de ensinar, novas maneiras de aprender. Porto Alegre: Artes Médicas.

Armstrong, T. (2001). Inteligências múltiplas na sala de aula (2a ed). Porto Alegre: Artes Médicas.

Brasil. Lei n. 9.394/96, de 20 de dezembro de 1996. Estabelece as diretrizes e bases da educação nacional. Diário Oficial [da] República Federativa do Brasil, Poder Legislativo, Brasilia, DF, 23 dez. 1996. p. 27833. Disponível em: < http://www6.senado.gov. $\mathrm{br} /$ legislacao $/$ ListaTextoIntegral.action?id $=75723>$. Acesso em: 23 jul. 2009.

Gardner,H.(1992).Estructuras delamente. México:FCE.

Gardner, H. (1994). Estruturas da mente: A teoria das inteligências múltiplas. Porto Alegre: Artes Médicas.

Gardner, H. (1995). Inteligências múltiplas: A teoria na prática. Porto Alegre: Artes Médicas.
Gardner, H., Kornhaber, L., \& Wake, K. (1998). Inteligência: Múltiplas perspectivas. Porto Alegre: Artmed.

Gardner, H. et al. (1999). La inteligencia práctica: Un nuevo enfoque para enseñar a aprender. Madrid: Santillana.

Gardner, H. (2000). La educación de la mente y el conocimiento de las disciplinas. Barcelona: Paidós.

Gardner, H. (2001). La inteligencia reformulada. Barcelona: Paidós.

Martínez, P. J., \& Suné, V. M. de (1999). Educação especial: A educação na diversidade. Ediciones Aljipe.

Paulon, S. M., de Lucca Freitas, L. B., \& Pinho, G. S. (2005). Documento subsidiário à política de inclusão (p. 19). Brasilia: Ministério da Educação, Secretaria de Educação Especial.

Piaget, J. (1958). Psicologia da inteligência. Rio de Janeiro: Fundo de Cultura.

Sternberg, R., \& Grigorenko, E. (2003). Inteligência plena. Porto Alegre: Artmed.

Visca, J. (1987). Clínica psicopedagógica e epistemologia convergente. Porto Alegre: Artes Médicas.

Veiga, E. C., \& Garcia, E. G. (2006). Psicopedagogia e a Teoria Modular da Mente: Uma nova perspectiva para a aprendizagem. São José dos Campos: Pulso.

Recebido: 23/02/2010

Received: 02/23/2010

Aprovado: 28/11/2010

Approved: $11 / 28 / 2010$ 